\title{
AA-UR 0104041
}

Approved for public release; distribution is unlimited.<smiles>CCCCCCCCC</smiles>

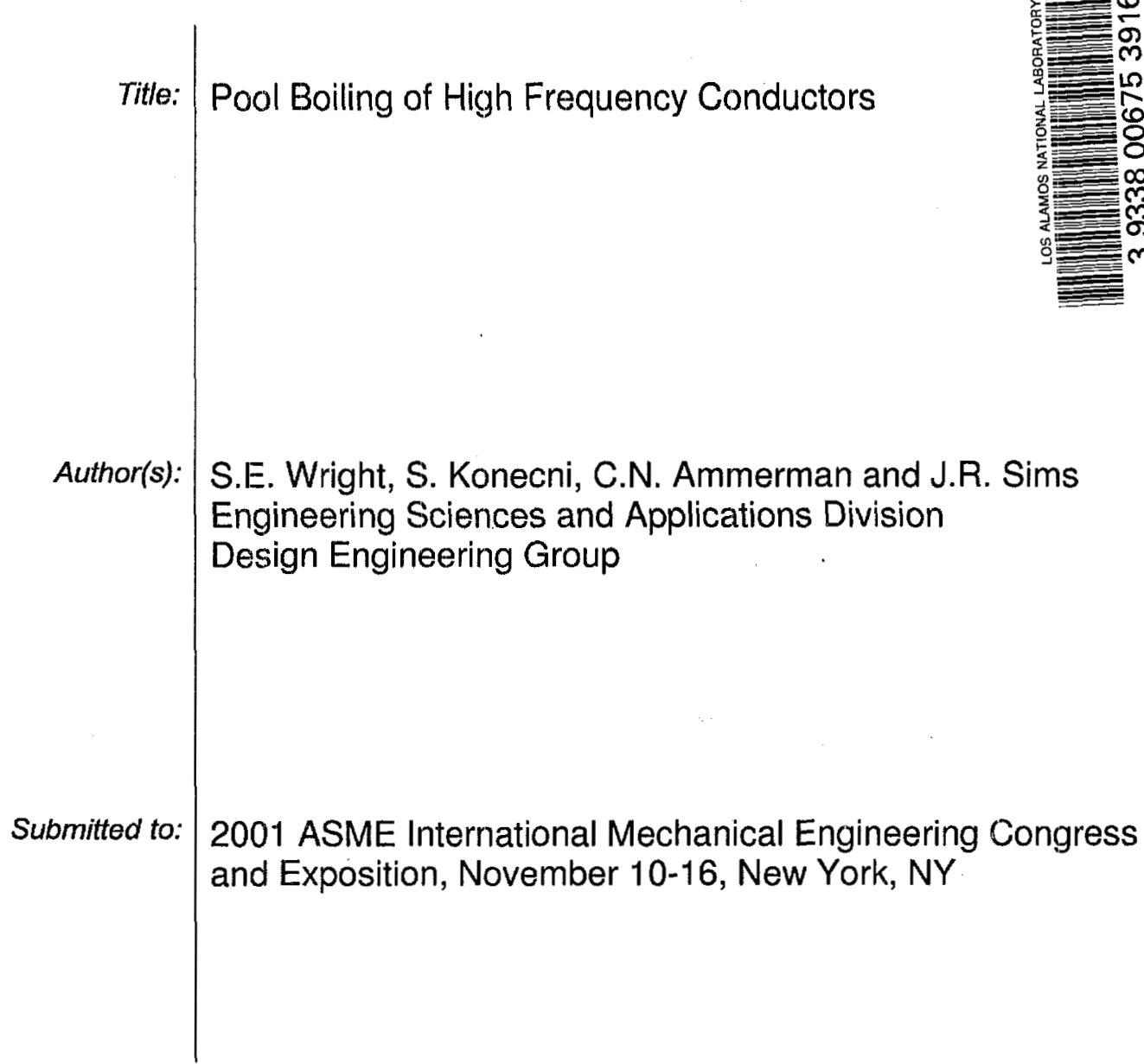

\section{Los Alamos}

\section{NATIONAL LABORATORY}

Los Alamos National Laboratory, an affirmative action/equal opportunity employer, Department of Energy undercontract W-7405-ENG-36. By acceptance of this arti retains a nonexclusive, royalty-free license to publish or reproduce the published fom ff this contribution, or to allow others to do so, for U.S Government purposes. Los Alamos National Laboratory requests that the publisher identify this article as work performed under the auspices of the U.S. Department of Energy. Los Alamos National Laboratory strongly supports academic freedom and a researcher's right to publish; as an institution, however, the Laboratory does not endorse the viewpoint of a publication or guarantee its technical correctness. 
IMECE2001/2-13-3-4

\title{
POOL BOILING OF HIGH-FREQUENCY CONDUCTORS
}

\author{
S.E. Wright', S. Konecni, C. N. Ammerman ${ }^{2}$, and J. R. Sims \\ Los Alamos National Laboratory \\ Engineering Sciences and Applications Division, Design Engineering Group \\ P.O. Box 1663, MS H821 \\ Los Alamos, NM 87545
}

\begin{abstract}
This study presents development of a unique, powerful method for cooling high-frequency, $\mathrm{AC}$ conductors that can benefit end users of transformer windings, electrical machine windings, and magnet coils. This method of heat removal involves boiling a dielectric, fluorinert refrigerant that is in direct contact with litz wire conductors. A pool boiling test vessel is constructed, which provides for temperature control of the pool of fluorinert liquid. The test vessel is fitted with viewing ports so that the experiments are observed and studied with the aid of high-speed photography. Tests are performed on a variety of litz wire conductors. The boiling heat transfer coefficient is dependent on the conductor surface roughness. The size of the features on the conductor surface depends on the single-strand wire gage from which the conductor is constructed. All tests are performed with the conductors mounted horizontally. These tests are performed using a DC power supply. The results of these experiments will aid in the design of future cooling systems.
\end{abstract}

\section{NOMENCLATURE}

CHF critical heat flux $\left[\mathrm{W} / \mathrm{cm}^{2}\right]$

$g$ gravitational acceleration $\left[\mathrm{m} / \mathrm{s}^{2}\right]$

$q_{\text {mex } x \text { sat }} \mathrm{CHF}$ at saturation temperature $\left[\mathrm{W} / \mathrm{cm}^{2}\right]$

$q_{\max , Z}$ CHF predicted by Zuber for infinite flat plate $\left[\mathrm{W} / \mathrm{cm}^{2}\right]$

$R \quad$ wire radius [m]

$R^{\prime} \quad$ non-dimensional wire radius, $R^{\prime}=R \sqrt{\frac{g\left(\rho_{f}-\rho_{g}\right)}{\sigma}}$

$U_{v} \quad$ voltage uncertainty [V]

$V \quad$ voltage $[\mathrm{V}]$

'Currently working with:

Cessna Aircraft Company, 5800 E. Pawnee, MS PAW, Wichita, KS 67210

${ }^{2}$ Author to whom correspondence should be addressed.

\author{
Greek Symbols \\ $\rho_{f} \quad$ liquid density $\left[\mathrm{kg} / \mathrm{m}^{3}\right]$ \\ $\rho_{g} \quad$ vapor density $\left[\mathrm{kg} / \mathrm{m}^{3}\right]$ \\ $\sigma \quad$ surface tension $[\mathrm{N} / \mathrm{m}]$
}

\section{INTRODUCTION}

This study investigates pool boiling as a cooling method for high frequency, AC, litz wire conductors. The power density of high-frequency transformer windings, electrical machine windings, and $\mathrm{AC}$ magnet coils could improve significantly through the use of this cooling technology. This increase in performance would permit a decrease in size and weight of power conversion equipment in vehicles, and boost electrical efficiency of stationary power conversion devices. Repetitively pulsed, high-field, research magnets could be made to reach even higher field strengths with greater duty cycles, and consume less power than their present-day counterparts. In addition, this cooling methodology could significantly impact AC "shaker" and "kicker" magnet technology for particle beam accelerators. These magnets could be made more efficient, more compact, and more reliable through the elimination of separately controlled water-cooling systems.

Heat removal from the high-frequency conductors in this study involves the boiling of a dielectric, perfluorinated liquid (Fluorinert, FC-72) that is in direct contact with the conductor. Fluorinerts are non-ozone-depleting, highly wetting, dielectric refrigerants. Fluorinerts have been used for several years as heat transfer fluids in electronic systems including immersion cooling of Cray supercomputers. These fluids are non-toxic, stable, and non-reactive and thus are compatible with most materials. Fluorinerts have been studied extensively and many 
of their properties are well-characterized. Relevant properties of FC-72 are shown in Table 1.

Table 1. Properties of Fluorinert Liquids

\begin{tabular}{|l|c|}
\hline Chemical Formula & $\mathrm{C}_{6} \mathrm{~F}_{14}$ \\
\hline Boiling Point $\left({ }^{\circ} \mathrm{C}\right)$ & 56.6 \\
\hline Dielectric Strength $(\mathrm{kV}, 2.54-\mathrm{mm}$ gap $)$ & 38 \\
\hline Liquid Density $\left(\mathrm{kg} / \mathrm{m}^{3}\right)$ & 1599 \\
\hline Liquid Specific Heat $\left(\mathrm{J} / \mathrm{kg} \cdot{ }^{\circ} \mathrm{C}\right)$ & 1121 \\
\hline Latent Heat $(\mathrm{J} / \mathrm{kg})$ & 94280 \\
\hline Liquid Thermal Conductivity $\left.\mathrm{W} / \mathrm{m} \cdot{ }^{\circ} \mathrm{C}\right)$ & 0.0545 \\
\hline Liquid Viscosity $(\mathrm{kg} / \mathrm{m} \cdot \mathrm{s})$ & $4.47 \times 10^{-4}$ \\
\hline Surface Tension $(\mathrm{N} / \mathrm{m})$ & $8.10 \times 10^{-3}$ \\
\hline
\end{tabular}

Pool boiling heat transfer using Fluorinert liquids is being examined in a number of areas. Hong et al. [1] examined the critical heat flux (CHF) of wires at pure-subcooled, gassaturated, and saturated states of FC-72. They also provided correlations for determining the CHF of cylindrical heaters at these states. Paschkewitz [2] investigated the long-term effects of high voltage electric fields on the physical and electrical properties of FC-72. He found no significant change in the properties of the FC-72 due to these electric fields.

Litz wires are examined in this effort because of their increased efficiency over solid conductors. At high frequencies, the $\mathrm{AC}$ current carried by a solid conductor is not uniformly distributed over its cross-section. In the case of a solid, round wire, the current density reaches its maximum at the wire's surface and a minimum at the center. This non-uniform distribution of current is known as the "skin effect." Eddy currents within the conductor cause the $\mathrm{AC}$ current to flow at the conductor's surface, therefore, the inner cross section of the wire is essentially unused. A large-cross-section conductor enables these eddy currents to circulate over significant surface areas resulting in wasted power and undesirable heating.

Litz wires carry higher current densities at lower AC resistances compared with solid conductors. These wires consist of a bundle of fine, separately insulated strands of wire. The term litz wire is derived from the German word Litzendraht meaning folded or turned-up stranded wire. Generally defined, it is a conductor constructed of individual, film-insulated wires braided together such that each strand tends to take all possible positions in the cross section of the conductor.

This multi-strand configuration of the litz wire minimizes the power losses resulting from the skin effect and eddy currents otherwise encountered in a solid conductor. Subdividing the conductor into individual, isolated strands and transposing them appropriately equalizes the flux linkages and reactances. This equalization produces more uniform current distribution in the conductor without significantly reducing the current carrying capability. Uniform current distribution and minimization of eddy currents results in a significant increase in conductor efficiency. Also, the braided nature of the litz wire cable provides grooves and cavities resulting in an increased number of nucleation sites creating an enhanced boiling surface.

The majority of pool boiling studies with cylindrical heaters have been performed using solid conductors. Heat transfer from solid conductors is often enhanced using techniques such as foamed channels, roughened surfaces, and surface vibration (Webb [3]). O'Connor and You [4] investigated a painting technique to generate surface microstructures (artificial cavities) to enhance the boiling surface. These artificial cavities are well known to promote enhanced nucleate pool boiling, but very little investigation has been done in the area of pool boiling enhancement of twisted cable bundles. The experiments that have been performed on cable bundles are often not twisted so they do not benefit from the large number of nucleation sites generated by the cavities created by the overlapping wires.

The goal of this study, therefore, is to examine the pool boiling heat transfer characteristics of litz wires immersed in saturated FC-72. Tests are performed on a variety of litz wire conductors mounted horizontally. The boiling heat transfer coefficient is dependent on the conductor surface roughness. The roughness of the conductor surface depends on the singlestrand wire gage from which the conductor is constructed. These tests are performed using a DC power supply.

\section{EXPERIMENTAL APPARATUS AND PROCEDURE}

A test facility was designed and constructed to maintain a pool of FC-72 at its saturation temperature, while allowing the observation of pool boiling from the litz wire conductors. A schematic of the test facility is shown in Fig. 1.

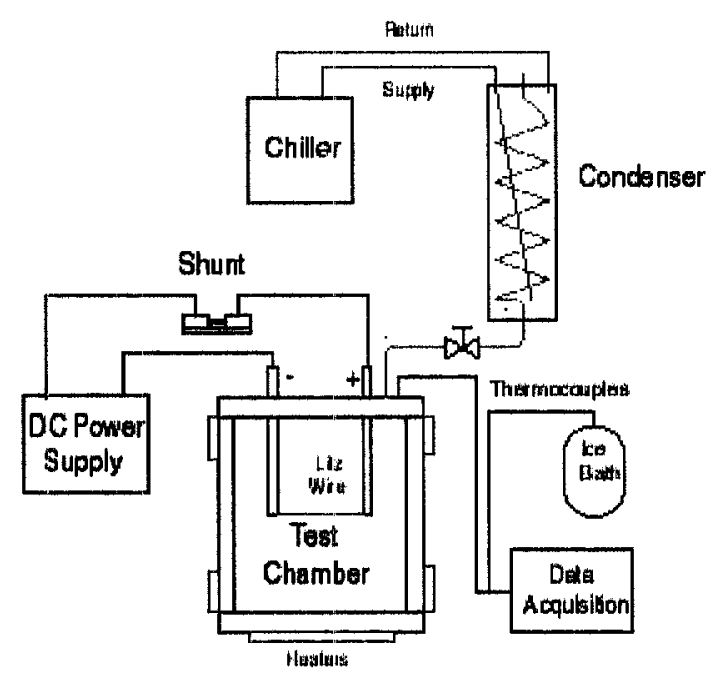

Fig. 1. Schematic of Experimental Apparatus. 
The experimental apparatus used for this investigation consists of a boiling chamber and an external condenser. An aluminum vessel (9 in. high, $10 \mathrm{in}$. OT) and $9 \mathrm{in}$ ) ID, is used for the boiling chamber. Three flexible heaters are secured to the test chamber, two 2 in. $\times 20$ in. $(400 \mathrm{~W})$ heaters on the sides and a 4 in, $x 8$ in. $(320 \mathrm{~W})$ heater on the bottom. These are used to de-gas the FC-72 and maintain the saturation temperature during testing. Insulation covers most of the test chamber. Two, 5-inch I exan windows are on the sides of the test chamber so that the boiling phenomena can be observed and photographed with a high-speed digital camera.

The lid of the botling chamber is made of $1 / 2$ inch aluminum plate. Attached to the lid of the vessel are 1 wo, 3/4-inch, highcurrent, insulated power feedthroughs that conduct the input power and affix the high-frequency conductors. Thermoconple ports, a pressure relief valve, and an electric barometer are also attached to lid of the test vessel. Also attached to the boiling chamber is a condenser that is open to the amosphere at the top. This allows dissolved gases to escape while condensing the working fluid. $A$ chiller maintains the shell side temperature of the condenser at $17^{\circ} \mathrm{C}$.

An $8-\mathrm{V}, 1000-\Lambda, \mathrm{DC}$ power supply is used to heat the lit: wire test specimens: This power supply is connected to a $\mathrm{PC}$ and controlled using data acquisition software. An HP 34970A data acquisition system connected to a PC running Lab View was used to collest data. 'Temperature measuremonts were made using ten, type-T' themocouples. Two thermocouples measure the bulk liquid temperature, one neasures chamber vapor temperature, one is attached to each of the power leedthroughs, and the other five thermocouples are attached to the litz wire test specimen. Bach themocouple has an extemal reterence junction placed in an ice batl. An Empro shunt is used to noasure the current delivered to the litz wire. The resistance of the shunt is 0.00005 .2 with an accuracy of $-10.25 \%$.

\section{Litz Wires Tested}

Five different lity wire configurations were investigated and are shown in Table 2. All wire samples were obtained from the New lingland lalectric Wire Company (NEEWWC). Of these configurations, two types of round wires and one type of rectangular wire werc examined, as shown in Fig. 2. The first type, Type 1, was a single bundle of polyurethane/rylon coated strands of wire in three sizes. The construction information refers to the number and gage of the wires that comprise the bundle. For example, a Type I wire bundle with a 17/28 construction is composed of 17,28 gage wire strands. The scoond type, Type 2, is bundle made up of three Type-1 bundles, each of which is composed of 35, 36-gage wire strands. The rectangular litz wire (Type 8 ) is constructed of 8 bundles of wire, Gach with 7 strands of 33 gage wire, which are then compressed into a rectangular shape.
Table 2. Litz Wire Specimens

\begin{tabular}{|c|c|c|c|c|}
\hline Type & Construction & $\begin{array}{c}\text { Nominal } \\
\text { Dometer } \\
\text { (in) }\end{array}$ & $\begin{array}{c}\text { Width } \\
\text { (in) }\end{array}$ & $\begin{array}{c}\text { Thickness } \\
\text { (in) }\end{array}$ \\
\hline 1 & $17 / 28$ & 0.065 & $\mathrm{n} / \mathrm{a}$ & $\mathrm{n} / \mathrm{a}$ \\
\hline 1 & $26 / 30$ & 0.064 & $\mathrm{n} / \mathrm{a}$ & $\mathrm{n} / \mathrm{a}$ \\
\hline 1 & $53 / 33$ & 0.066 & $\mathrm{n} / \mathrm{a}$ & $\mathrm{n} / \mathrm{a}$ \\
\hline 2 & $3 \times 35 / 36$ & 0.073 & $\mathrm{n} / \mathrm{a}$ & $\mathrm{n} / \mathrm{a}$ \\
\hline 8 & $8 \times 7 \times 33$ & $\mathrm{n} / \mathrm{a}$ & 0.094 & 0.045 \\
\hline
\end{tabular}

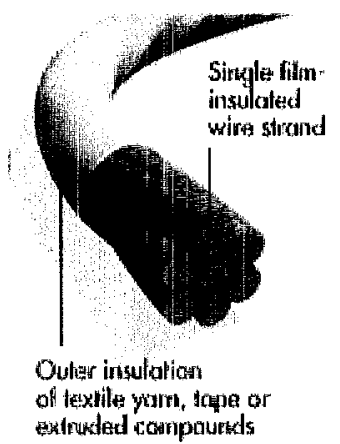

Type 1

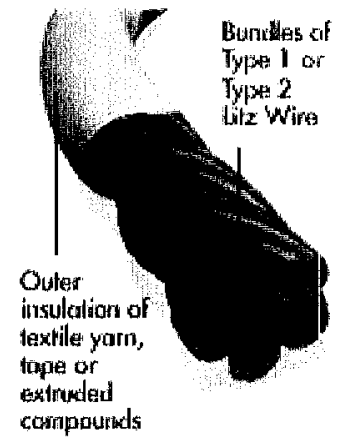

Iype 2

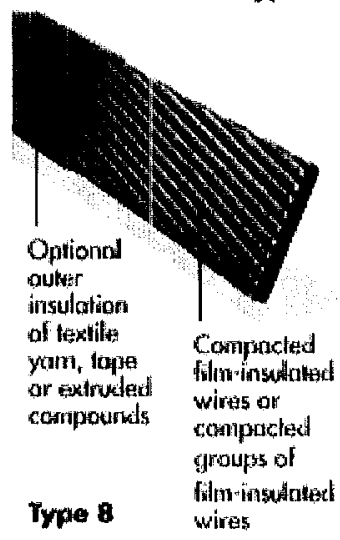

lig. 1. Examples of Iitz Wite Cable Bundles Manufactured by New Fingland Electric Wire Company.

The shapes and cross sectional views of the Lity wires examined are shown in Fig. 3. All the litz wire bundles tested had an equivalent, nominal wire gage of 16 , when compared to that of a standard wire. For the purpose of calculating surface area for the multi-stranded litz wires, cach configuration was assumed to have a circular diameter equal to that of its nominal diameter. For the rectangular litz. wire, the surface area was computed using its perimeter based on width and thickness. A 16-gage, solid copper wire was also tested so that it could be compared with the litz wire results. 


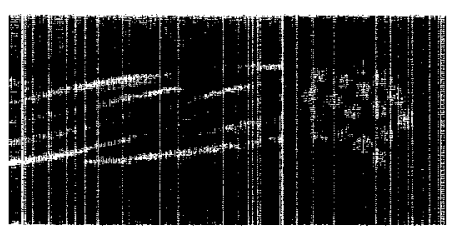

Type $1(17 \times 28)$

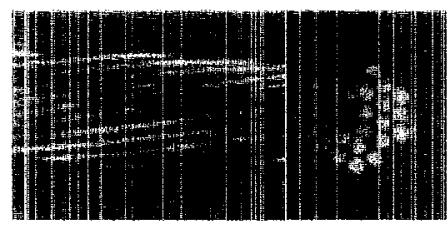

Type $1(26 \times 30)$

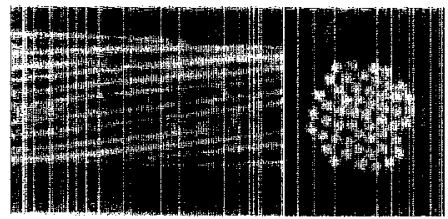

Type $1(53 \times 33)$

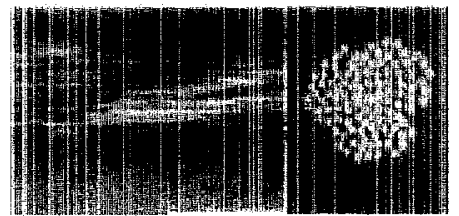

Type $2(3 \times 3.5 \times 36)$

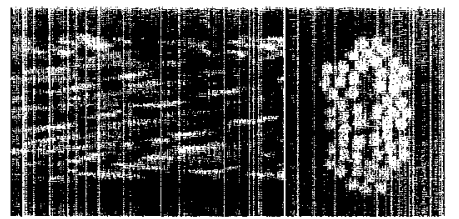

'Yye $8(8 \times 1 \times 33)$

Iig. 3. Photographs of I it $z$ Wire Specimens (all photos have same length scale).

The length of the litz wires tested was set at 6 in. This length was based on heat loss calculations to the $3 / 4$-inch copper power feedthroughs. Using a 1-D analysis, conduction losses to the copper feedthroughs were estimated to impact up to $0.75 \mathrm{in}$. from the ends of the lit\% wire test specimen. In order to minimize the effect of the feedthroughs on the heat transfer data, therefore, thermocouples attached to the lit $\%$ wires were placed in the wire at a distance equal to or greater than 1 inch from the feedihrough.

\section{Preparation of Test Specimens}

Lity wire specimens were prepared by cutting pieces of wire $7.5 \mathrm{in}$. long and placing the cnds into a $60 / 40$-tin/lead solder pot at $375 \%$ The melted solder removes the polyurethane/nylon insulation from the individual strands of wite. Copper washers were then soldered onto the ends of the lity wire. 20-gage copper leads were soldered to each copper washer to measure the voltage across the litz wire. Five, type-T, 40-gage thermocouples were mounted to the specimen, spaced l-inch apart starting from the center of the wire. Five thermocouples were used to reduce the amount of thermal interference while maintaining the ability to detect $\mathrm{CHF}$ before burn out. Tests performed with fewer thermocouples often reached burn out before CHF was detected.

The thermocouples were attached to the specimen using Omegabond 101 epoxy loaded with copper powder to increase the epoxy's thermal conductivity. The mixture ratio of epoxy to copper powder was 2 to 1 . Ench thermocouple was attached in the center of the wire bundle with epoxy covering the thermocouple junction. Figure 4 shows thermocouples attached to a typical lit\% wire specimen that is mounted between the power feedthroughs.

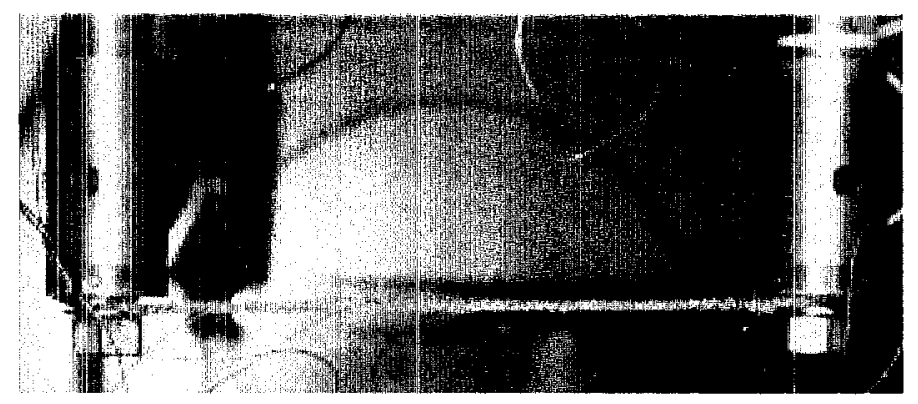

Fig. 4. I itz Wire Specimen Connected to Power Feed hroughs.

\section{Test Procedure}

Power is supplied to the electric heaters attached to the boiling chamber to initiate boiling on the sides of the chamber. The test liquid is allowed to boil vigorously for approximately two hours to remove dissolved gasses. After degassing, the power to the chamber heaters is reduced so that boiling on the chamber walls ceases, however, the bulk liquid is maintained at saturation conditions, typically $51.4^{\circ} \mathrm{C}$ at 11.8 psia.

The data acquisition software controls the power input to the litz wire and the collection of heat transfer data. The software is programmed to increase the heat flux by controlling the supply voltage in the litz wire. Voltage is increased by 0.1 $V D C$ at the beginning of the boiling curve (near incipience) and when the conductor approaches CHF. Throughout the rest of the boiling curve, the voltage increased by 0.3 VIDC. The voltage is incremented to the next power level after the wire has reached stcady state. Steady state is determined by calculating the averages of 120 consecutive data points for each thermocouple on the conductor, and comparing them to the averages of a 
second set of 120 data points. When the amount of temperature change in each of the five thermocouples is less then $0.2^{\circ} \mathrm{C}$ from one average to the next, steady state is assumed. After the wire reaches steady state the voltage, current, and temperatures are recorded and the voltage is increased. The determination of CHF is made by monitoring the litz wire temperature for a sudden increase of greater than $15^{\circ} \mathrm{C}$. The heat flux value at CHF was obtained by adding half of the heat flux increment to the previous steady state heat flux.

Five different litz wires and one solid copper wire were tested. Two specimens of each configuration were placed in the test chamber. Each litz wire cable was tested three times to ensure repeatability in the data and to confirm that the wire had not been damaged by burnout. All tests are performed with the conductors mounied horizontally. The rectangular Litz wire was tested in two horizontal orientations: with the wide side upward (horizontal), and with the narrow side upward (vertical).

\section{Uncertainty Analysis}

The method of Kline and McClintock [5] was used to determine the uncertainty in the experimental apparatus. The uncertainty of the measured voltage was determined by using the HP 34970A specifications for a maximum of I VDC:

$$
U_{v}= \pm(0.00015 \mathrm{~V}+50 \mathrm{mV})+0.00005 \mathrm{~V}
$$

where $V$ is the voltage level. The $1000-\mathrm{A}, 50 \mathrm{mV}$ Empro shunt has an uncertainty of $\pm 0.25 \%$. Using these two values the accuracy of the calculations for the current was determined to be $2.77 \mathrm{~A}$. These values were then used to determine the accuracy of the heat flux calculations, The heat flux uncertainties for each litz wire tested are shown in Table 3. These uncertainties were calculated for a voltage of I VDC and a current of $500 \mathrm{~A}$.

Table 3. Uncertainty Values for Litz Wire

\begin{tabular}{|c|c|c|}
\hline Type & Construction & Uncertainty $\left( \pm W / \mathrm{cm}^{2}\right)$ \\
\hline 1 & $17 / 28$ & 0.352 \\
\hline 1 & $26 / 30$ & 0.356 \\
\hline 1 & $53 / 33$ & 0.346 \\
\hline 2 & $3 \times 35 / 36$ & 0.314 \\
\hline 8 & $8 \times 7 \times 33$ & 0.258 \\
\hline
\end{tabular}

In order to improve their accuracy, each thermocouple was calibrated using a precision RTD and a constant temperature bath. The thernocouples were placed in the bath and measurements were recorded. Temperature measurements were taken from 50 to $100^{\circ} \mathrm{C}$ because this was the normal range of temperatures for the experiment. This measured data set was used to create a linear curve fit for each thermocouple. An accuracy of $\pm 0.1^{\circ} \mathrm{C}$ was calculated for the thermocouples with a resolution of $0.025^{\circ} \mathrm{C}$ for the RTD and a maximum error introduced by the curve fit of $\pm 0.073^{\circ} \mathrm{C}$.

\section{RESULTS AND DISCUSSION}

During the experiments, high-speed digital images (shown in Fig. 5) were taken of the wires at boiling incipience, nucleate boiling, and film boiling. From these images it was determined that the thermocouples caused the wire to heat differently at their location. This was discovered by the fact that the bubbles leaving the location of thermocouples were larger than those leaving other parts of the wire.

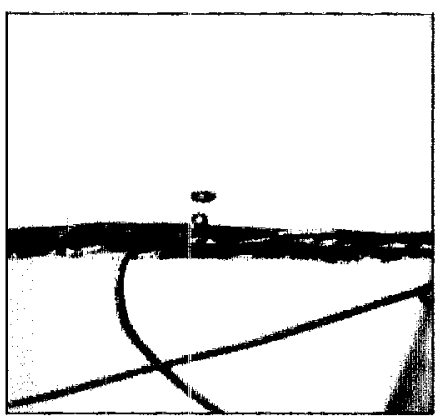

Boiling Incipience

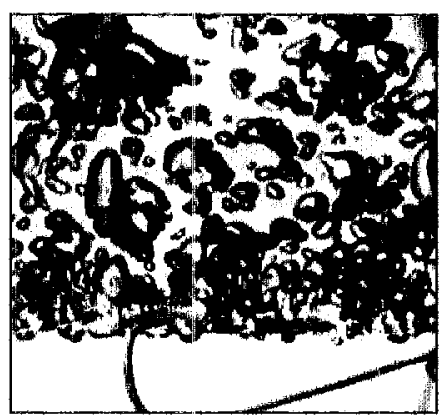

Nucleate Boiling

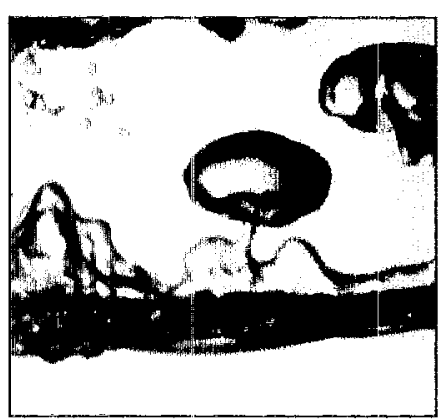

Film Boiling

Fig. 5. Boiling On Litz Wire Specimen. 

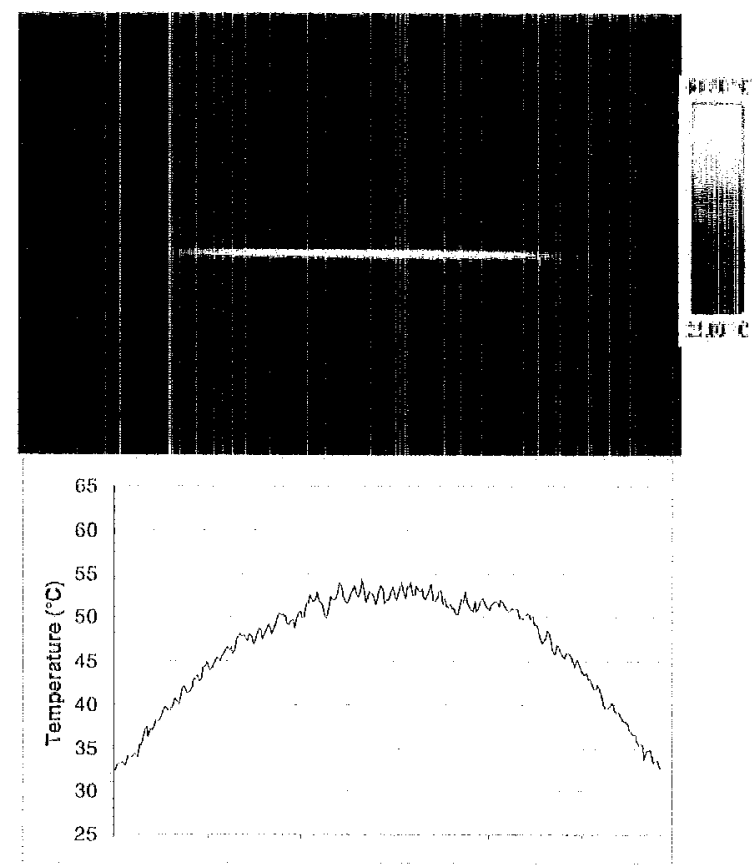

Without Thermocouples
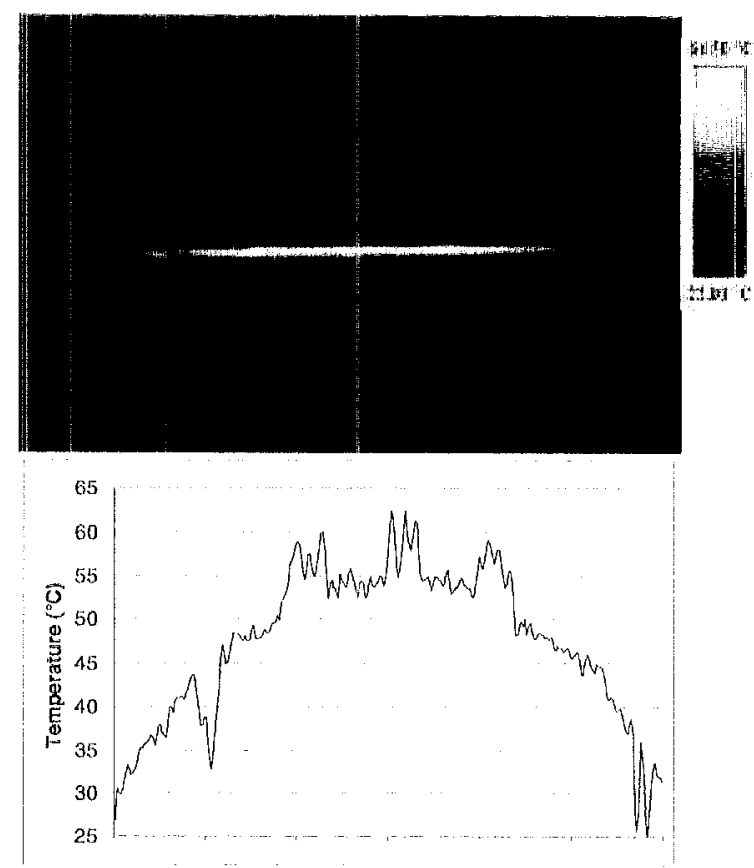

With Thermocomples

Fig. 6. IN Images of a rype 8 I.itu Wire, With and Without, llhermocouples.

(A wire passing between the litz wire and the Ill camera causes the downward spike in the right-hand figure.)

\section{Infrared Imaging}

In order to determine the effect of the themocouples on the heating of the litz wire, infrared images were taken. 'T'hese images, shown in Fig 6 for the Type 8 litz wire, were taken in air at a wire power of approximately $1.2 \mathrm{~W}$. (The downward spike in the figure with thermocouples is caused by wire passing between the litz wire and the IR camera.) The emissivity of the lit\% wire was determined to be 0.66 . This was found by placing a simall piece of Scotch Super $33+$ tape on the wire. The tape has a known emissivity of 0.95 . The temperature of the tape is assumed to be the same as the wire. A temperature measurement is taken on the tape and the camera is then moved to measure the tenperature on the wire right next to the tape. The wire emissivity is then iddusted until the two temperatures are the same.

After taking infrared images of all the litz, wires, with and without thermocouples, it was found that the thermocouples calused a local increase in temperature on the wires ranging from 5 to $10{ }^{\circ} \mathrm{C}$. This means that the measured litz wire temperatures are conservative. A possible remedy for this effect would be to use a non-invasive temperature measurement sensor such as an infraretl detector.

\section{Heat Transfer Performance}

Boiling curves for each of the wires tested are shown in Fig. 7. The heat flux dissipated is shown on the ordinate. The abscissa is the corresponding surface temperature rise of the heating element above the saturation temperature of the liquid. The heater temperature used in this plot is the average of the 5 temperatures measured along the wire.

The solid wire exhibited the second best nucleate boiling heat tratsfer performance of the 7 configurations tested. Even though it does not benefit from the enhanced surface structure of the litz wires, the solid wire does not have the added thermal resistance of the litz wire insulation. Heat transfer from the wire strands within a litz wire is impeded because each strand is individually insulated. The more wires in a bundle, therefore, the more difficult it is for the heat to be dissipated.

The Type 2 (3×35/36) demonstrated the best heat transfer performance in the nucleate boiling regime. The Type 2 wire is composed of the smallest wire gage, thus providing the most favorable surface structure for boiling enhancement. In addition, even thought the Type 2 litz wire is composed of 105 individual wire strands, it is constructed with 3 separate bundles of 35 wires each. It is possible that this construction reduces the distance from an individual strand in the center of the Type 2 wire to the surface. 


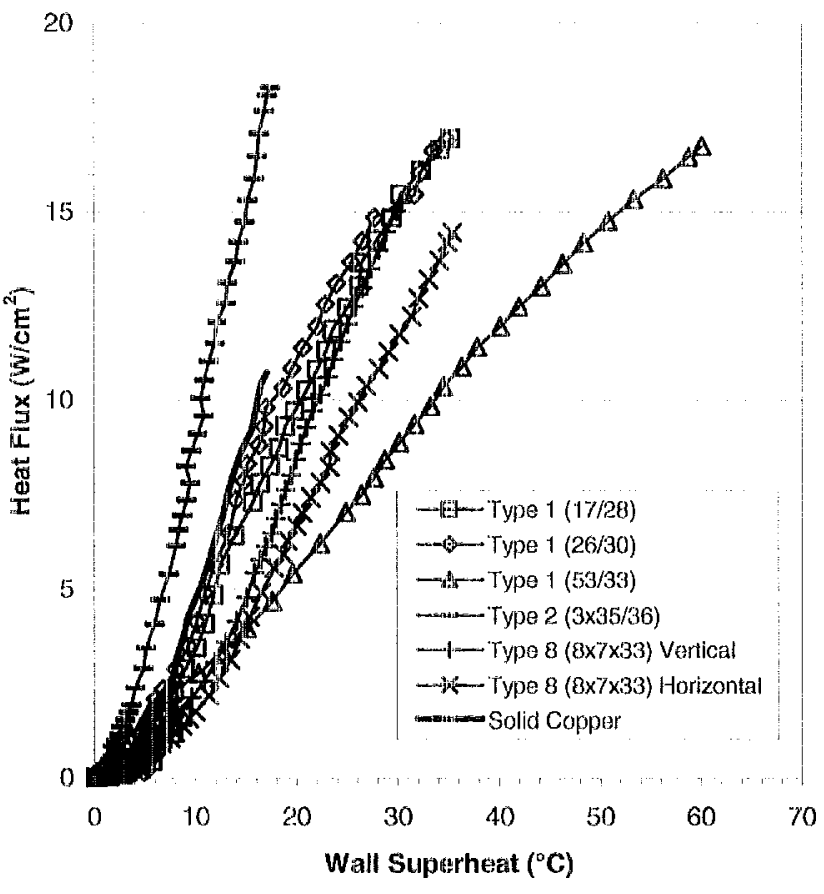

Iig. 7. Jioiling Curves for 'Test Specimens.

The comparison between the two Type 8 configurations shows that the vertical orientation performs better than the horizontal. This is expected since the horizontal orientation results in a larger downward facing flat area where vapor can collect and impede liquid flow back to the surface.

\section{Critical Heat Flux Predictions}

Experimental and predicted CHIF values for the wires tested are shown in Table 4. Critical heat flux predictions for a solid wire of the same diameter as each specimen were calculated using the correlation of Hong et al. |1 |.

$$
\frac{q_{\max , \mathrm{sat}}}{q_{\mathrm{milx}, Z}}=0.89+1.01 e^{-2.18 \sqrt{R}}
$$

where $q_{\text {max }}$ is $\mathrm{CHI}^{-}$predicted by Zuber for intinite flat plate and $R$ ' is dimensionless wire radius defined by:

$$
R^{\prime}=R \sqrt{\frac{g\left(\rho_{j}-\rho_{g}\right)}{\sigma}}
$$

\begin{tabular}{|c|c|c|c|}
\hline Wire & $\begin{array}{c}\text { Surface } \\
\begin{array}{c}\text { Area } \\
\left(\mathrm{cm}^{2}\right)\end{array}\end{array}$ & $\begin{array}{c}\text { CHF } \\
\text { Experiment } \\
\left(W / \mathrm{cm}^{2}\right) \\
\end{array}$ & $\begin{array}{c}\text { CHF } \\
\text { Predicted } \\
\left(\mathbf{W} / \mathrm{cm}^{2}\right)\end{array}$ \\
\hline Type $1(17 / 28)$ & 7.90 & 17.5 & 14.5 \\
\hline Type $1(26 / 30)$ & 7.78 & 16.7 & 14.5 \\
\hline Type I (53/33) & 8.03 & 18.4 & 14.5 \\
\hline Type $2(3 \times 35 / 36)$ & 8.88 & 19.2 & 14.3 \\
\hline $\begin{array}{l}\text { Type } 8(8 \times 7 \times 33) \\
\text { Horizontal }\end{array}$ & 10.76 & 15.2 & 13.1 \\
\hline $\begin{array}{l}\text { Type } 8(8 \times 7 \times 33) \\
\text { Vertical }\end{array}$ & 10.76 & 15.4 & 13.1 \\
\hline Solid Copper & 7.78 & 11.0 & 14.5 \\
\hline
\end{tabular}

Table 4. Critical Heat Flux

Enhancement in CHF for the litz wires ranges from 1.15 to 1.34 times the predicted CHF for a solid wire of the same size. This enhancement is likely due to the enhanced surface structure caused by the braided nature of the small strands of wire comprising the litz wire. The Type $2(3 \times 35 / 36)$ has the largest enhancement. In addition, the orientation of the rectangular litz wire had little effect on how the wire performed. The rectangular wire's diameter was approximated using the hydraulic diameter.

All litz wire configurations show CHF enhancement over that of the solid copper wire ranging from 38 to $75 \%$. The solid wire's experimental CHF, however, is $24 \%$ below its predicted value. This degradation in CFF performance is attributed to the method of thermocouple attachment. The thermocouples are fixed to the wires using epoxy, which causes local hot spots as seen in the IR images. These hot spots can lead to reduced values of CHF. It is possible, therefore, that the experimental litz wire CHF values will increase if a non-invasive temperature measurement technique is used.

\section{CONCL.USIONS}

This study presents the pool boiling heat transfer results for litz wires immersed in saturated FC-72. The following conclusions resulted from this study:

(a) The braided nature of the litz wires provides a favorable surface structure for boiling enhancement. This enhancement can be realized as litz wire bundles are configured such that the heat transfer resistance from the center of the bundle to the surface is not too large.

(b) The CHF from the litz wires is significantly enhanced over that of a solid wire. This enhancement is also due to the enhanced surface structure of the braided wire strands.

(c) The use of epoxy to attach thermocouples to the wires caused local hot spots on the wires. These hot spots resulted in a degradation in heat transfer and CHF performance. 


\section{ACKNOWLEDGME:NTS}

The authors would like to thank New England Electric Wire Company of Lisbon, NH for the use of their litz wire images.

\section{REFERENGIES}

I. Hong, Y.S., A.mmerman, C.N., and You, S.M., 1998, "Effects of Length Scale, Subcooling, and Dissolved Gas Content on the Pool Boiling Critical Heat Flux of Cylindrical Heaters," Proc. 11th Int. Heat Transfer Conf., 2, pp. 389-394.

2. Paschkewitz, J.S., 1998, "Exposure Testing of Dielectric Liquids for Aircraft EHD Heat Exchanger Application," Conference on Electrical Insulation and Dielectric Phenomena, 1, pp. 166-169

3. Webb R.L., 1994, Principles of Enhanced Heat Transfer, John Wiley \& Son Inc., New York.

4. O'Connor, J.P., and You, S.M., 1995, "A Painting Technique to Enhance Pool Boiling Heat Transter in Saturated FC.72,".J. Heat Transfer, 117, pp. $387-393$

5. Kline, S.J., and McClintock, F.A., 1953, "Describing Uncertainties in Single-Sample Experiments," Mechanical Engineering, "75 pp. 3-8. 